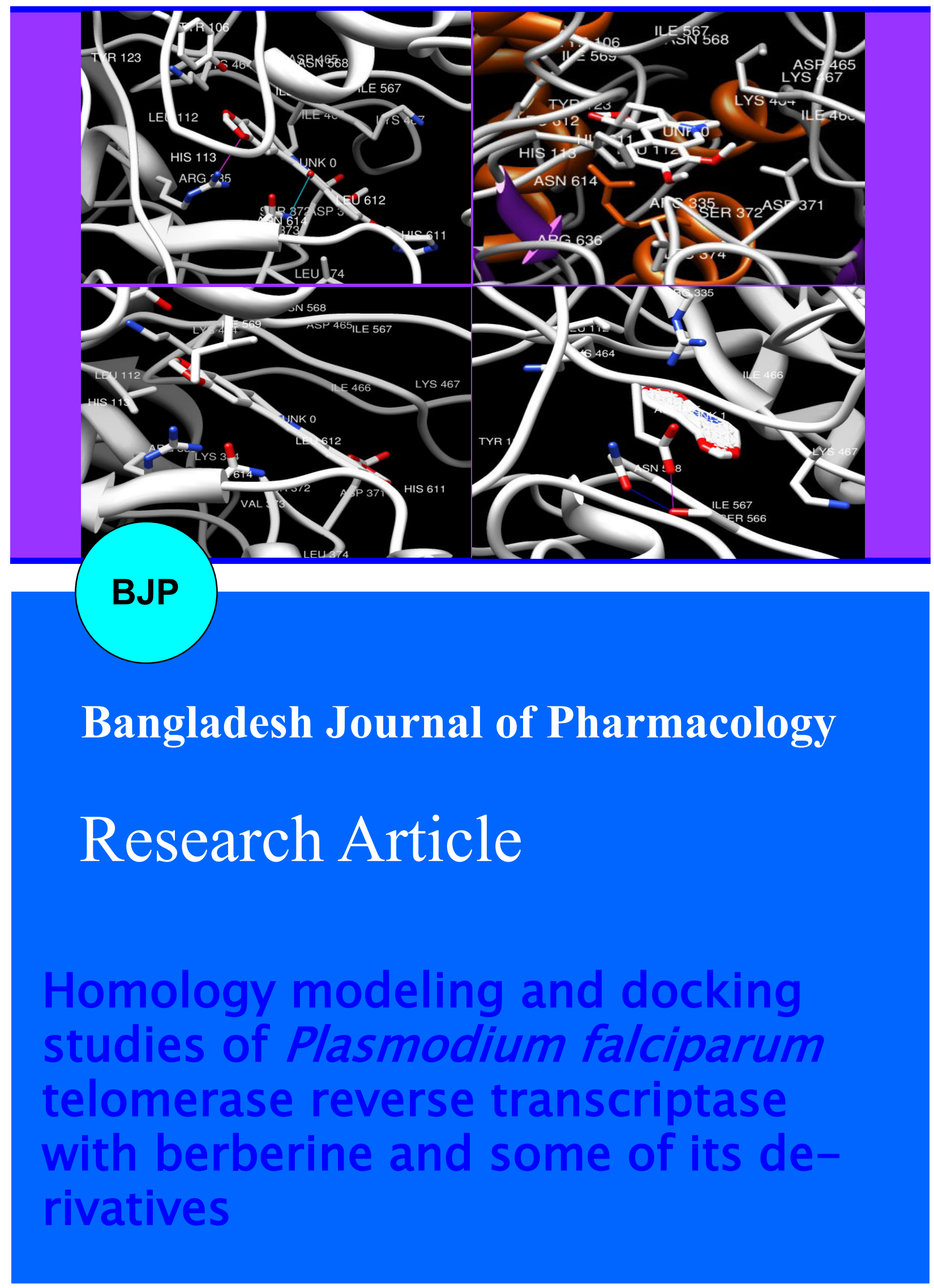




\title{
Homology modeling and docking studies of Plasmodium falciparum telomerase reverse transcriptase with berberine and some of its derivatives
}

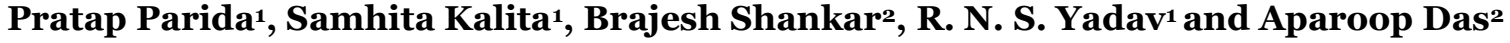 \\ ${ }^{1}$ Bioinformatics Infrastructure Facility, Centre for Studies in Biotechnology, Dibrugarh University, Assam 786004 , \\ India; ${ }^{2}$ Department of Pharmaceutical Sciences, Dibrugarh University, Assam 786 004, India.
}

\begin{tabular}{|c|c|}
\hline \multicolumn{2}{|l|}{ Article Info } \\
\hline Received: & 4 January 2014 \\
\hline Accepted: & 13 January 2014 \\
\hline Available Online: & 25 February 2014 \\
\hline \multicolumn{2}{|c|}{ DOI: 10.3329/bjp.v9i1.17535 } \\
\hline \multicolumn{2}{|c|}{$\begin{array}{l}\text { Cite this article: } \\
\text { Parida P, Kalita S, Shankar B, Yadav } \\
\text { RNS, Das A. Homology modeling and } \\
\text { docking studies of Plasmodium falcipa- } \\
\text { rum telomerase reverse transcriptase } \\
\text { with berberine and some of its deriva- } \\
\text { tives. Bangladesh J Pharmacol. 2014; } \\
\text { 9: } 96-104 \text {. }\end{array}$} \\
\hline
\end{tabular}

\section{Abstract}

The telomerase reverse transcriptase (TERT) sequence from Plasmodium falciparum provides valuable information for the design of specific antitelomerase drugs. The present study deals with the interaction of pfTERT against berberine derivatives to derive novel analogues. Berberine intercalates DNA, thereby inhibits DNA synthesis and PfTERT. This indicated that $P$. falciparum telomerase might be a potential target for malaria chemotherapy. The nature of the interactions between A three-dimensional structural model of PfTERT was constructed using multiple sequence alignment and homology modeling procedures, followed by extensive molecular dynamics calculations. The analogues of berberine were successfully docked into the binding pocket of the protein. The hydrogen bonds were analyzed along with the binding energy was observed. The binding energy were found to be $-8.4,-8.4$, $-8.2,-11.3,-10.5,-3.6,+186.2,-6.0,-1.1$ and -7.5 in $\mathrm{Kcal} / \mathrm{mol}$ with reference drugs. The least binding energy was found to be $-11.3 \mathrm{Kcal} / \mathrm{mol}$ which determines that the most effective analogue. As a result this can be used as antiplasmodial drug.
\end{abstract}

\section{Introduction}

The telomerase reverse trancriptase (TERT) protein of Plasmodium falciparum is one of the few well-defined targets in malarial chemotherapy. This plasmodial protein contains all of the canonical motifs of RTs as well as conserved amino acids known to be critical for the RT activity. TERT contains unique and variable $\mathrm{N}$ and C-terminal extensions that flank a central RT like domain (Figueiredo et al., 2005; Autexier et al., 2006). PfTERT has received considerable attention as it is the target of berberine and its derivatives used treatment of $P$. falciparum infection. The rapid emergence of antifolate resistant $P$. falciparum has unfortunately compromised the clinical utilities of the drugs, and thus highlights the urgent need to search for new effective antifolate antimalarials (Rastelli et al., 2000). The PfTERT predicted molecular weight is $280 \mathrm{kDa}$, which is almost the three times larger in size of other TERTs. In the N-terminal half of PfTERT has three motifs specific to TERTs: GQ/N, QFP and T (Figueiredo et al., 2005; Autexier et al., 2006; Lingner et al., 1997; Malik et al., 2000; Friedman et al., 1999). Amino acids known to be specific for telomerases were in PfTERT: Arg in motif 1 , an aromatic residue (Phe or Tyr) following the two critical Asp residues in motif $C$ and a motif similar to the Trp-X-Gly-XSer/ Leu in motif E.

Depending upon the difference in size of the Plasmodial TERT results from increased distance between nearly all motifs. Human Genome Center, Tokyo, Japan has found that PfTERT contains several 
NLS (Nuclear Localization Signal)-like motifs (Figueiredo et al., 2005). The k-nearest neighbors classifier (k-NN) algorithm predicts that PfTERT primary sequence refers to a protein that has $78.3 \%$ probability to be nuclear (Figueiredo et al., 2005; Xia et al., 2000). The blood stage cycle takes 48 hours to be completed. It begins with the invasion of non-infected erythrocytes by merozoites present in the bloodstream. When th erythrocyte, the parasite will undergo three stages: ring (0-18 hours), trophozoite (18-38 hours) and schizont (38-48 hours) stages. $S$ phase begins in the trophozoite stage, 28-31 hours after merozoite invasion. Nuclear division occurs throughout schizogony, which leads to the production of up to 32 individual merozoites. At the end of the 48 hours cycle, erythrocytes burst releasing merozoites and the cycle starts a new (Figueiredo et al., 2005). It has been shown that telomerase activity is detectable by TRAP only in trophozoite and schizont stages (Sriwilaijareon et al., 2002). During schizogony, the number of PfTERT foci increased proportionally to the number of nuclei. After schizonts become fully mature (48 hours) and merozoites are released into the blood stream, PfTERT was no longer detectable. PfTERT was chosen as it is a gene in $P$. falciparum that has the characteristics of the protein component of telomerase. It contains structural features that are common with the telomerases known in other species: RT motifs, telomerase-specific motifs and $\mathrm{pI}>10$. PfTERT contains several stretches of 10-20 basic amino acids, such as asparagines, which are encoded by A-rich codons (Figueiredo et al., 2005). Among all P. falciparum polymerases, the TERT gene is the one that contains more $\mathrm{A}+\mathrm{T}$ nucleotides, more repeats and a higher increase in size relative to the yeast orthologue, suggesting that PfTERT sequence is less functionally constrained than that of the other polymerases. These repeats are therefore more likely to reflect the propensity of the $P$. falciparum genome by polymerase slippage events due to the presence of stretches of $\mathrm{A}$ and/or $\mathrm{T}$, instead of selection process that leads to increased gene length. As a result the extreme $\mathrm{A}+\mathrm{T}$ richness of Plasmodia genomes $(80 \% \mathrm{~A}+\mathrm{T}$ for $P$. falciparum) may favour the increase in gene size and led to the accumulation of the repetitive regions in non-essential gene areas (Achaz et al., 2001; Levinson et al., 1997). In P. falciparum cell extracts, telomerase can be efficiently inhibited by RT type of drugs, such as nucleoside analogues (i.e. berberine and its derivatives) (Figueiredo et al., 2005; Weinrich et al., 1997). These drugs are now a day's being tested on in vitro cultures and preliminary data show killing of $P$. falciparum parasites after 3-5 blood stage cycles at micromolar concentrations (Bottius et al., 1998). However, they were unable to generate a knock-out of the PfTERT gene, supporting the idea that telomerase activity is needed for blood stage parasite proliferation (Cong et al., 2002).
A prophylactic therapy based on plasmodial telomerase inhibitors might be possible (Arnot et al., 1998; Lin et al., 2008). Berberis aristata is commonly known as "Daru haldhi and Chitra" is spinous herb native to northern Himalaya region. The plant is commonly distributed from Himalayas to Srilanka, Bhutan and hilly areas of Nepal. Its hypoglycemic, antibacterial, antifungal, antipyretic, anti-inflammatory, anti-oxidant, hepatoprotective, antimalarial, anti-cancer was proven by pharmacological studies. The plant fruit is edible and it is rich in vitamin $C$. The phytochemical studies proves that the plant B. Aristata mainly contains yellow colored alkaloids berberine, oxyberberine, aromoline and a protoberberine alkaloid palmatine, oxycanthine etc. which acts as inhibitory activity against PfTERT protein of $P$. falciparum. Berberine has been used for the treatment of malaria as an antimalarial drug (Sriwilaijareon et al., 2002; Lin et al., 2008; Sheng et al., 1997; Vennerstrom et al., 1988). Berberine (5,6-dihydro9,10-dimethoxybenzo[g]-1,3-benzo-dioxolo[5,6a]quinolizinium), a yellow benzylisoquinoline alkaloid, is a constituent of Coptis chines (Cong et al., 2002). Berberine is chief alkaloid from roots and stem-bark of Berberis species. It is produced mostly from roots of B. aristata (5\% in roots and $4.2 \%$ in stem-bark), B. petiolaris $(0.43 \%)$, B. vulgaris, B. aquifolium, B. thunbergii and B. asiatica. The Chinese herbs, the primary sources are B. sargentiana, Phellodendron amurense and Coptis chinensis. Coptis chinensis rhizomes and its related species used as its substitutes have about $4-8 \%$ berberine, while Phellodendron amurense bark has about half as much, at 2 $-4 \%$ berberine (Sheng et al., 1997). The inhibitory effects of three protoberberine alkaloids on E. coli revealed that the sequence of their antimicrobial activity was greater in comparison to the others which is berberine > coptisine $>$ palmatine. The pharmacological studies of berberine include anti-inflammation, antidiarrhetic, antimalarial, and even antimicrobial activities (Vennerstrom et al., 1988; Janbaz et al., 2000; Yan et al., 2007). In Vietnam, it is being collected from 14 medicinal plants and used in traditional treatment of the disease. Twenty-four extracts from these plants were found to have antiplasmodial effects inhibiting the growth of the chloroquine-resistant $P$. falciparum strain FCR-3 with EC50 values of less than $10 \mu \mathrm{g} / \mathrm{mL}$. Telomerase activity is synchronized in $P$. falciparum during its erythrocytic cycle using the telomerase repeat amplification protocol (TRAP) (Sriwilaijareon et al., 2002). It is reported that berberine extract inhibited telomerase activity in a dose dependent manner over a range of 30$300 \mu \mathrm{M}$. It indicated that $P$. falciparum telomerase might be a potential target for future malaria chemotherapy (Sriwilaijareon et al., 2002; Sharma et al., 2011; Dutta et al., 1962; Gardner et al., 2002; Singh et al., 2010). Hence to block the telomerase activity of the $P$. falciparum the docking study of the berberine derivatives were per- 
formed with newly modeled protein of TERT protein with the help of homology modeling.

\section{Materials and Methods}

\section{Sequence retrieval}

The pfTERT protein sequence was downloaded from NCBI (http:/ / www.ncbi.nlm. nih.gov) having gene ID 23479392. The sequence was taken for Homology Model building since there was no structure found for pfTERT in the Protein Data Bank.

\section{Template identification}

The template identification for homology model building of the selected protein se-quence was took place in Exome Horizon. The protein "oxidoreductase-crystal structure of $P$. falciparum glutathione reductase" having PDB ID 1ONF was found to be the best template based on the e-value i.e. 1.00 .

\section{Homology modeling of P. falciparum TERT}

The structure of the TERT protein of P. falciparum was obtained from homology modeling simulations. The model was constructed by alignment of $P$. falciparum TERT primary sequences of which the crystal structures are already known. The alignment of $P$. falciparum TERT sequence was carefully checked by using the available sequence alignment evaluation functions within MODELLER 9v8 and by superimposing the structurally conserved regions of the available TERT crystal structures.

\section{Ligand preparation}

The ligands were drawn using Moldraw tool of Exome ${ }^{\mathrm{TM}}$ Horizon in 2D and were converted into 3D before submission of docking. The Molecular formulae and the chemical properties of all the selected ligands were given in Table I. The ADMET (absorption, distribution, metabolism, excretion and toxicolgy) properties were studied and were given in Table II.

\section{Protein-ligand docking studies}

Protein-ligand docking is used to check the structure, position and orientation of a protein when it interacts with small molecules like ligands. Protein-ligand docking aims to predict and rank the structures arising from the association between a given ligand and a target protein of known 3D structure. Protein-ligand docking module is further divided into different parts for user convenience like receptor preparation, ligand preparation, binding site analysis, dock and analysis.

The inhibitors were docked into the active site of PfTERT, using the final structure obtained from the explicit solvent molecular dynamics calculations. The protein-ligand docking was performed using Lamarckian genetic algorithm using default parameter (Morris et al., 1998; Morris et al., 1996). This is the same as the standard genetic algorithm except that, before scoring, each conformation (gene) is subjected to energy minimization. The next population is then originated by members of energy-minimized population. The name "Lamarckian" refers to the failed genetic theory of JeanBaptiste Lamarck, who held that an organism could pass on changed experienced in its lifetime to its offspring. This theory was eventually abandoned in favor of Mendel's now familiar laws of inheritance. The LGA (Lamarckian Genetic Algorithm) is faster than both simulated annealing and the standard genetic algorithm, and it allows the docking of ligands with more degrees of freedom. The number of automated docking runs, number of individuals in the population, maximum number of energy evaluations and number of generations were set to 10, 50, 2500 and 3000 respectively. All the molecules successfully docked to the binding site.

\section{Results and Discussion}

The analogues were successfully docked into the binding pocket. The binding energy was observed in the range of $+186.2--11.3 \mathrm{Kcal} / \mathrm{mol}$. The key result in a docking log file (DLG) are the docked structure or conformation found at the end of each run, the energies of these docked structures and their similarities to each other. The DLG file provides docked conformations, orientations and the binding energies. The similarity of docked structures is measured by computing the rootmean-square deviation (RMSD) between the coordinates of selected molecular conformation with the molecular conformation having lowest interaction energy which is ranked on top. Clusters are created based on the comparison of conformations using RMSD values. The docking results consist of the PDBQT (The pdbqt format is ' $p d b$ ' plus ' $q$ ' for partial charge and ' $t$ ' for atom type.) of the transformed 3D Figure 1: Binding energy calculation of the ligands Cartesian coordinates of the ligand atoms as docked to the receptor molecule (Ramachandran et al., 1963). The binding energy of the selected ligands were plotted in the graph and from the graph (Figure 1) the binding energy of all the active sites were observed among which the best ligand which shows better activity in all the active site was found to be cyanodihydroberberine. The aminoacids and the drug interactions were given in the Figure 2A-I. In this study, it was targeted the putative Plasmodial telomerase reverse-transcriptase gene, PfTERT. PfTERT contains the most conserved telomerase motifs, but interestingly is predicted to encode an unusually large TERT. PfTERT is not detectable in early ring forms (G1like phase); however in parasites that have begun DNA synthesis, PfTERT forms a single discrete spot at the nuclear periphery. Attempts to disrupt PfTERT gene failed suggesting that telomerase is essential for the 
Table I

Berberine derivatives along with its chemical properties analyzed using Exome Horizon

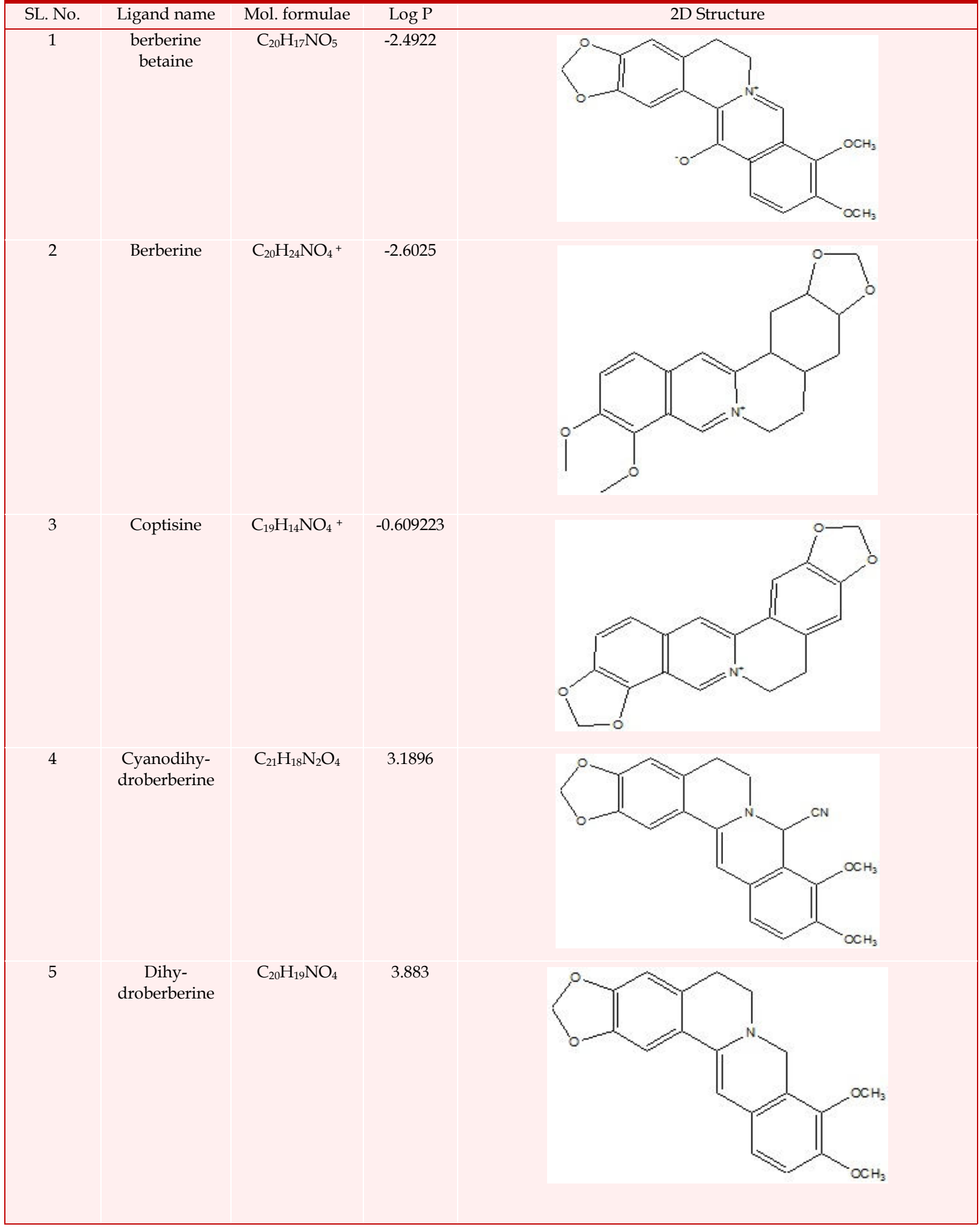




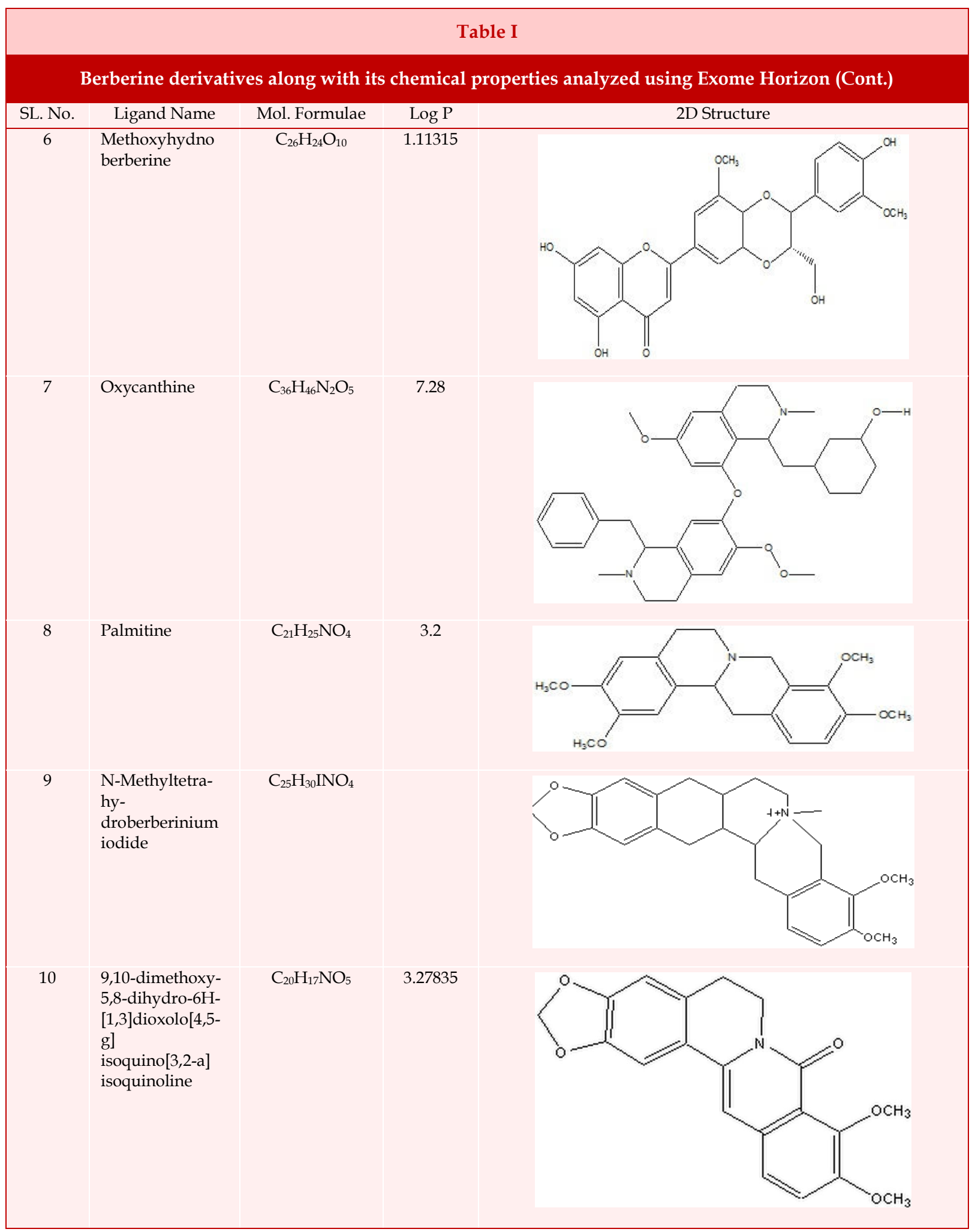


Table II

The ADMET properties analyzed using Exome Horizon

\begin{tabular}{|c|c|c|c|c|}
\hline Ligand Name & $\begin{array}{l}\text { Lipinsky's } \\
\text { filter }\end{array}$ & $\begin{array}{l}\text { Bioavaila- } \\
\text { bility }\end{array}$ & $\begin{array}{l}\text { Lead likeli- } \\
\text { ness }\end{array}$ & $\begin{array}{l}\text { Ghose } \\
\text { filter }\end{array}$ \\
\hline Berberine betaine & Green, 4 & Red, 7 & Red, 5 & Red, 3 \\
\hline Berberine & Green, 4 & Red, 7 & Red, 5 & Red, 3 \\
\hline Coptisine & Green, 4 & Red, 7 & Red, 5 & Red, 3 \\
\hline Cyanodihydroberberine & Green, 4 & Red, 7 & Red, 5 & Red, 4 \\
\hline Dihydroberberine & Green, 4 & Red, 7 & Red, 5 & Red, 4 \\
\hline Methoxyhydnocarpin & Green, 4 & Red, 7 & Red, 3 & Red, 3 \\
\hline Oxycanthine & Yellow, 2 & Red, 5 & Red, 4 & - \\
\hline Palmatine & Green, 4 & Red, 7 & Red, 6 & Red, 4 \\
\hline N-Methyltetrahydro-berberinium iodide & Green, 4 & Red, 7 & Red, 4 & Red, 2 \\
\hline $\begin{array}{l}\text { 9,10-dimethoxy-5,8-dihydro-6H-[1,3]dioxolo[ }[4,5-\mathrm{g}] \\
\text { isoquino[3,2-a]isoquinoline }\end{array}$ & Green, 4 & Red, 7 & Red, 5 & Red, 4 \\
\hline
\end{tabular}

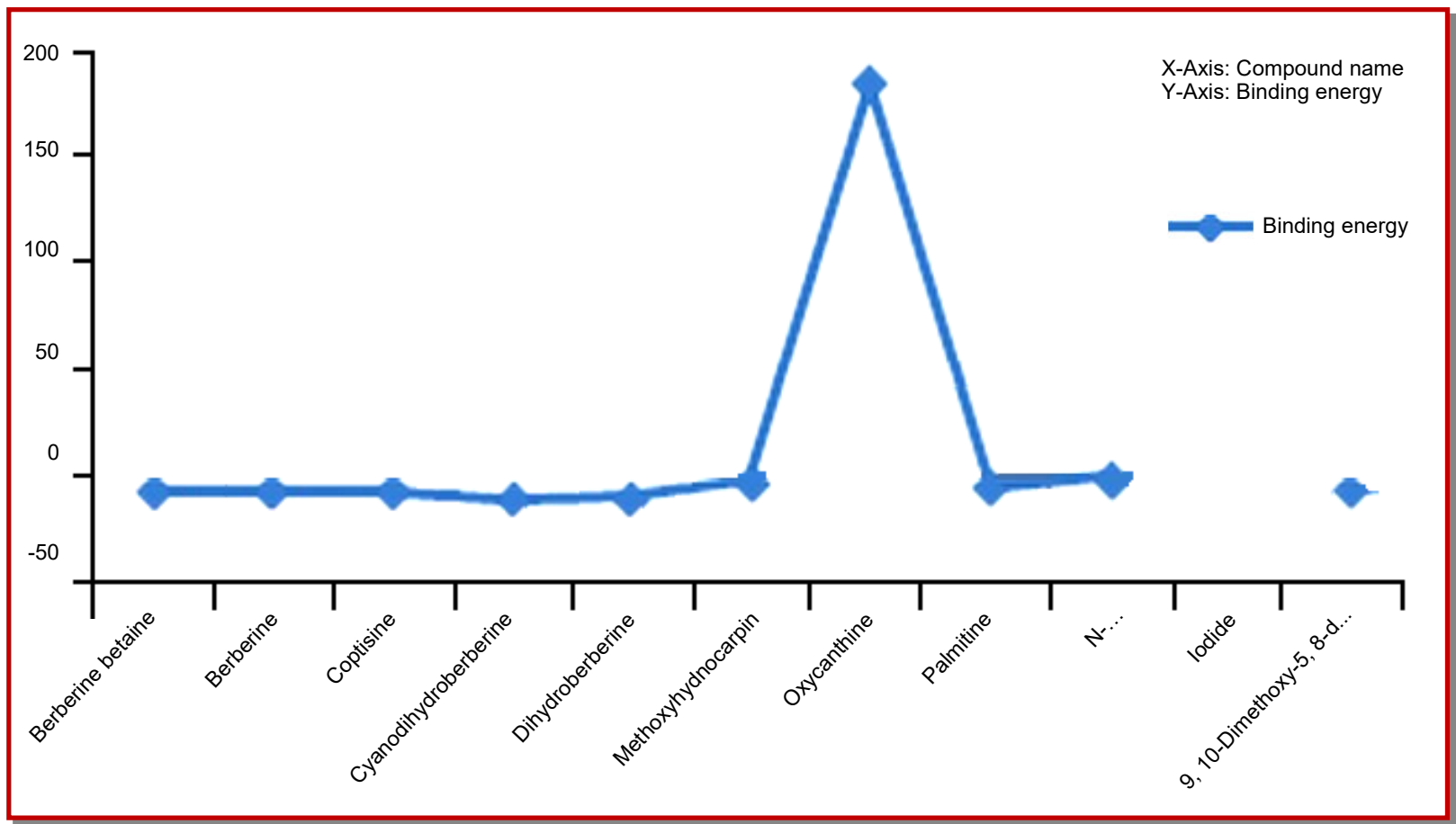

Figure 1: The binding energy calculation of the drugs against the model

parasite viability. So the current research paper deals with the study of blocking the telomerase activity of the protein pfTERT which may result in blocking the DNA synthesis in the parasite. It was found an unknown gene of $P$. falciparum which is a protein component of telomerase, named here PfTERT. The protein sequence was taken as target sequence. The template identification process was taken place to find the desired template structure of the target sequence. The template was found to be crystal structure of P. falciparum glutathione reductase whose PDB ID is 1ONF. One homology model of the same was developed using Modeller 9v8 since there was no actual 3D structure in the PDB (Protein Data Bank). Berberine is an isoquino- line alkaloid, present in roots and stem-bark of Berberis species. Berberine based formulations, are widely used in traditional systems of medicine including, Ayurveda and traditional Chinese medicine. Berberine has treated wide range of pharmacological activities including; antihypertensive, anti-inflammatory, anti-oxidant, antidepressant, anti-cancer, anti-diarrheal, cholagouge, hepatoprotective, antimicrobial and above all, antimalarial (Singh et al., 2010). Berberine and its analogues have been studied extensively for their different anti-infective and pharmacological effects. (Sinha et al., 2009; Wang et al., 2009; Zhang et al., 2010; Qi et al., 2010; Iwazaki et al., 2010). Recent studies, have thrown light on antidiabetic and hypolipidemic 


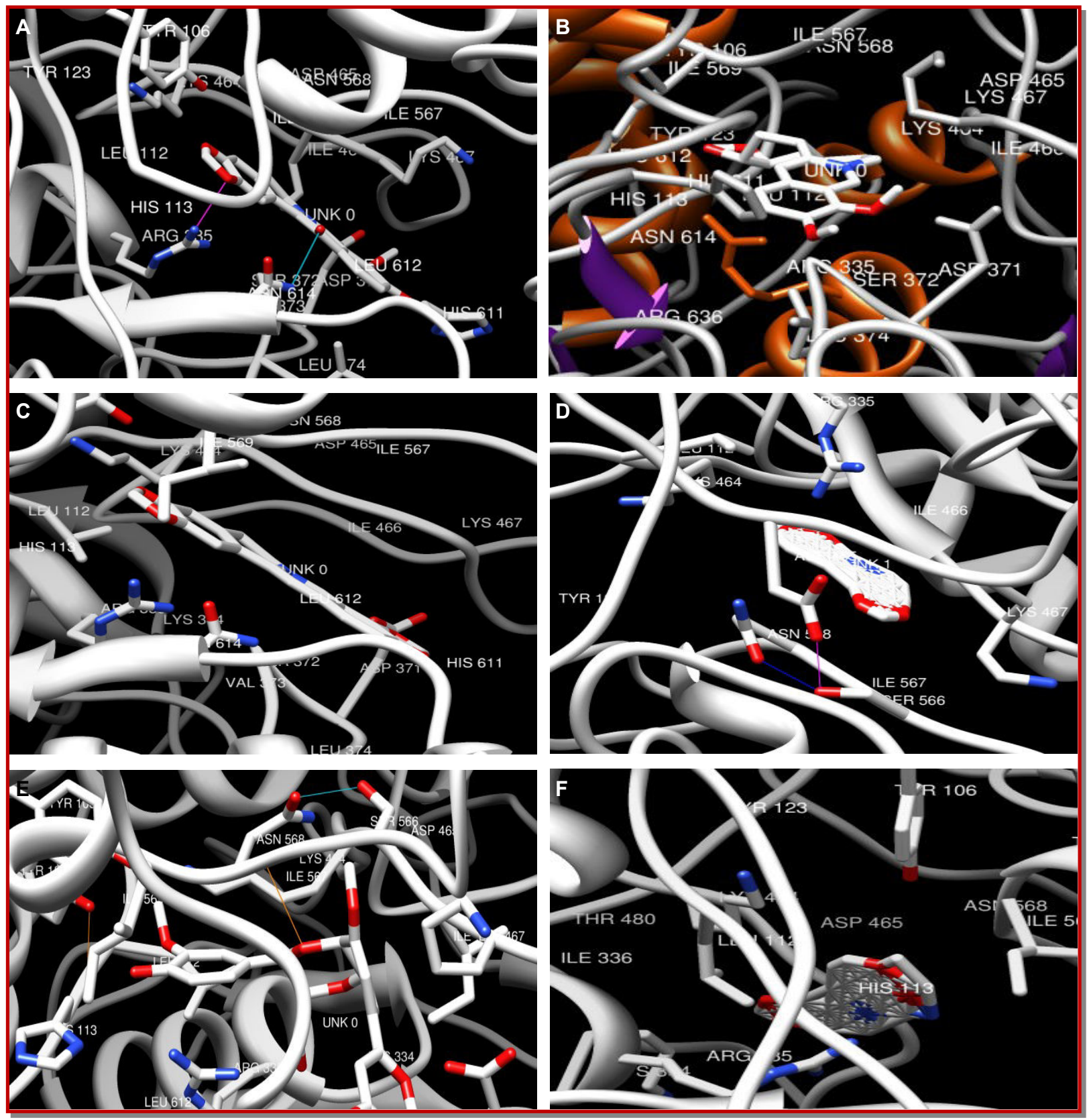

Figure 2: The interactions of the berberine betaine (A), berberine (B), coptisine (C), cyanodihydroberine (D), dihydroberbeine (E), methoxyhydroberberine $(\mathrm{F})$, oxycanthine $(\mathrm{G})$, palmitine $(\mathrm{H})$, and 9,10-dimethoxy-5,8-dihydro-6H-[1,3]dioxolo[4,5-g] isoquino[3,2a] isoquinoline (I) against the proteins. The colors below were represented as the interacting hydrogen bonds between the protein and the drugs

activities of the alkaloid. Berberine has been proved clinically in the treatment of oriental sore, diarrhea, trachoma diabetes mellitus type 2, hypercholesterolemia, and congestive cardiac failure. The present research work, discusses the antiplasmodial activity of barberine and its analogues which will be potential for drug-development.

Berberine has definite potential as drug, since it possesses diverse pharmacological properties. Previous studies established utility of berberine as antibacterial agent. As per recent studies, the striking effect of berberine is on DNA synthesis of $P$. falciparum.

\section{Acknowledgement}

The authors gratefully acknowledge Bioinformatics Infrastructure Facility (BIF) funded by Department of Biotechnology, Government of India, at Centre for Studies in 


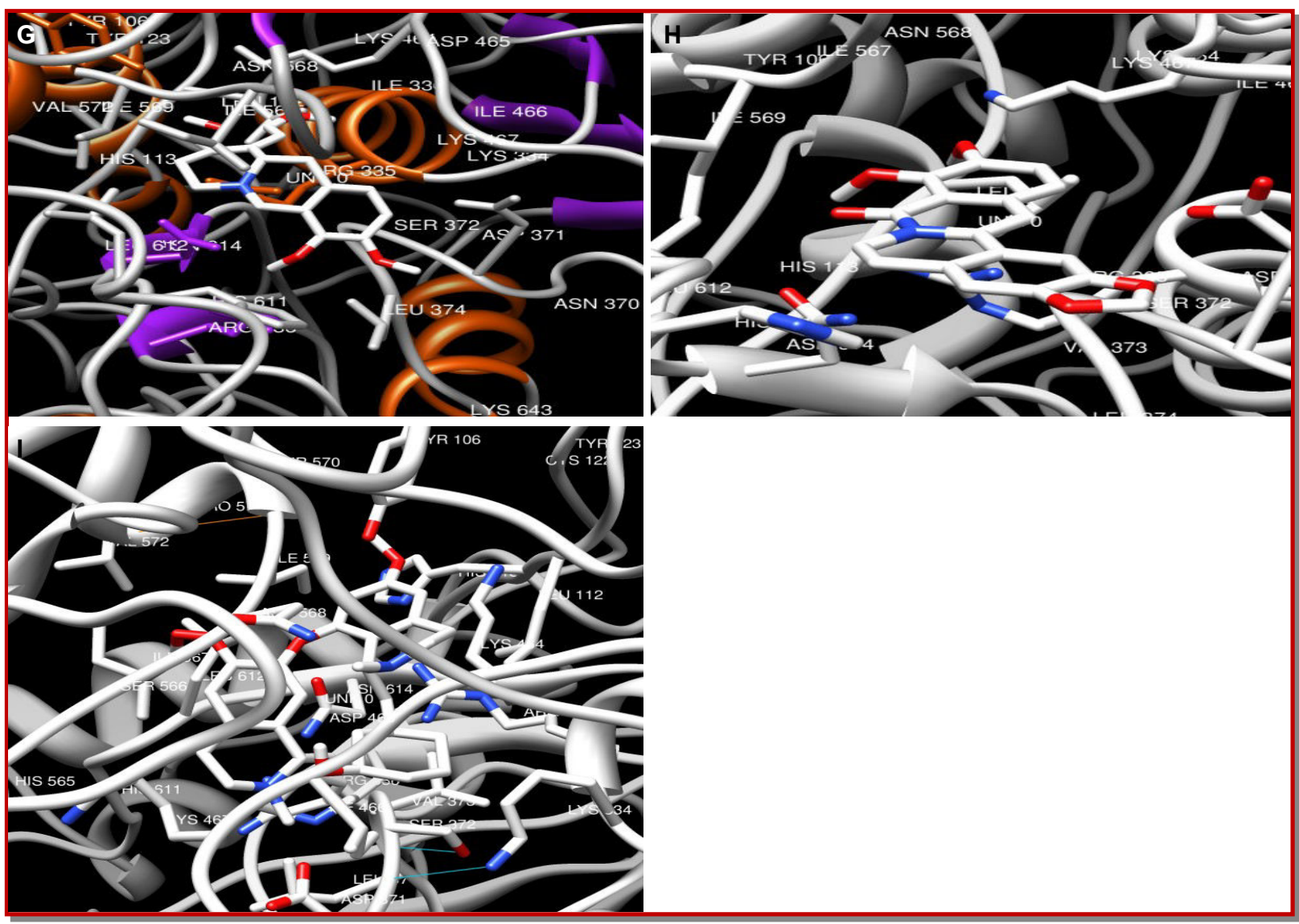

Figure 2: The interactions of the berberine betaine $(A)$, berberine $(B)$, coptisine $(C)$, cyanodihydroberine $(D)$, dihydroberbeine $(E)$, methoxyhydroberberine $(\mathrm{F})$, oxycanthine $(\mathrm{G})$, palmitine $(\mathrm{H})$, and 9,10-dimethoxy-5,8-dihydro-6H-[1,3]dioxolo[4,5-g] isoquino[3,2a] isoquinoline (I) against the proteins. The colors below were represented as the interacting hydrogen bonds between the protein and the drugs (Continued)

Biotechnology, Dibrugarh University.

\section{References}

Achaz G, Netter P, Coissac E. Study of intrachromosomal duplications among the eukaryote genomes. Mol Biol Evol. 2001; 18: 2280-88.

Arnot DE, Gull K. The Plasmodium cell-cycle: Facts and questions. Ann Trop Med Parasitol. 1998; 92: 361-65.

Autexier C, Lue NF. The structure and function of telomerase reverse transcriptase. Ann Rev Biochem. 2006; 75: 493-517.

Bottius E, Bakhsis N, Scherf A. Plasmodium falciparum telomerease: De novo telomere addition to telomeric and nontelomeric sequences and role in chromosome healing. Mol Cell Biol. 1998; 18: 919-25.

Cong YS, Wright WE, Shay JW. Human telomerase and its regulation. Microbiol Mol Biol Rev. 2002; 66: 407-25.

Dutta NK, Panse MV. Usefulness of berberine (an alkaloid from Berberis aristata) in the treatment of cholera (experimental). Int J Med Res. 1962; 50: 732-36.

Figueiredo LM. The unusually large Plasmodium telomerase reverse transcriptase localizes in a discrete compartment associated with the nucleolus. Nucl Acids Res. 2005; 33: 1111 -22 .

Friedman KL, Cech TR. Essential functions of aminoterminal domains in the yeast telomerase catalytic subunit revealed by selection for viable mutants. Genes Develop. 1999; 13: 2863-74.

Gardner MJ, Hall N, Fung E, White O, Berriman M, Hyman RW, Carlton JM, Pain A, Nelson KE, Bowman S, Paulsen IT, James K, Eisen JA, Rutherford K, Salzberg SL, Craig A, Kyes S, Chan MS, Nene V, Shallom SJ, Suh B, Peterson J, Angiuoli S, Pertea M, Allen J, Selengut J, Haft D, Mather MW, Vaidya AB, Martin DM, Fairlamb AH, Fraunholz MJ, Roos DS, Ralph SA, Mcfadden GI, Cummings LM, Subramanian GM, Mungall C, Venter JC, Carucci DJ, Hoffman SL, Newbold C, Davis RW, Fraser CM, Barrell B. 2002. Genome sequence of the human malaria parasite Plasmodium falciparum. Nature 2002; 419: 498-511.

Iwazaki RS, Endo EH, Ueda-Nakamura T, Nakamura CV, Garcia LB, Filho BP. In vitro antifungal activity of the berberine and its synergism with fluconazole. Antonie Van Leeuwenhoek. 2010; 97: 201-05.

Janbaz KH, Gilani AH. Studies on preventive and curative effects of berberine. Fitoterapia 2000; 71: 25-33. 
Levinson G, Gutman GA. Slipped-strand mispairing: a major mechanism for DNA sequence evolution. Mol Biol Evol. 1997; 4: 203-21.

Lin JP, Yang JS, Wu CC, Lin SS, Hsieh WT, Lin ML, Yu FS, Yu CS, Chen GW, Chang YH, Chung JG. Berberine induced down-regulation of matrix metalloproteinase-1, -2 and -9 in human gastric cancer cells (SNU-5). In vivo. 2008; 22: 223-30.

Lingner J, Hughes TR, Shevchenko A, Mann M, Lundblad V, Cech TR. 1997. Reverse transcriptase motifs in the catalytic subunit of telomerase. Science 1997; 276: 561-67.

Malik HS, Burke WD, Eickbush TH. Putative telomerase catalytic subunits from Giardia lamblia and Caenorhabditis elegans. Gene 2000; 251: 101-08.

Morris GM, Goodsell DS, Halliday RS, Huey R, Hart WE, Belew RK, Olson AJ. Automated docking using a Lamarckian Genetic Algorithm and empirical binding free energy function. J Comput Chem. 1998; 19: 1639-62.

Morris GM, Goodsell DS, Huey R, Olson AJ. Distributed automated docking of flexible ligands to proteins: Parallel applications of AutoDock 2.4. J Comput Aided Mol Design. 1996; 10: 293-304.

Qi M, Feng Y, Dai DZ, Li N, Cheng YS, Dai Y. CPU86017, a berberine derivative, attenuates cardiac failure through normalizing calcium leakage and down regulated phospholamban and exerting anti-oxidant activity. Acta Pharmacologica Sinica. 2010; 31: 165-74.

Ramachandran GN, Ramakrishnan C, Sasisekharan V. Sterochemistry of polypeptide chain configurations. Int $\mathrm{J} \mathrm{Mol}$ Biol. 1963; 7: 95-99.

Rastelli G, Sirawaraporn W, Sompornpisut P, Vilaivan $\mathrm{T}$, Kamchonwongpaisan S, Quarrell $\mathrm{R}$, Lowe G, Thebtaranonth Y, Yuthavong Y. Interaction of pyrimethamine, cycloguanil, WR99210 and their analogues with Plasmodium falciparum dihydrofolate reductase: Structural basis of antifolate resistance. Bioorg Med Chem. 2000; 8: 1117-28.

Sharma K, Ranjan B, Neelam C, Birendra S, Kumar SN. Berberis aristata: A review. Int J Res Ayurveda Pharm. 2011; 2: 38388.
Sheng WD, Jiddawi MS, Hong XQ, Abdulla SM. Treatment of chloroquine-resistant malaria using pyrimethamine in combination with berberine, tetracycline or cotrimoxazole. East Afr Med J. 1997; 74: 283-84.

Singh A, Duggal S, Kaur N, Singh J. Berberine: Alkaloid with wide spectrum of pharmacological activities. J Nat Prod. 2010; 3: 64-75.

Sinha R, Kumar GS. Interaction of isoquinoline alkaloids with an RNA triplex: Structural and thermodynamic studies of berberine, palmatine, and coralyne binding to Poly(U). Poly (A) $\left(^{*}\right)$ Poly(U). J Physical Chem. 2009; 113: 13410-20.

Sriwilaijareon N, Petmitr S, Mutirangura A, Ponglikitmongkol M, Wilairat P. Stage specificity of Plasmodium falciparum telomerase and its inhibition by berberine. Parasitol Int. 2002; 51: 99-103.

Vennerstrom JL, Klayman DL. Protoberberine alkaloids as antimalarials. J Med Chem. 1988; 31: 1084-87.

Wang YX, Wang YP, Zhang H, Kong WJ, Li YH, Liu F, Gao RM, Liu T, Jiang JD, Song DQ. Synthesis and biological evaluation of berberine analogues as novel up-regulators for both low-density-lipoprotein receptor and insulin receptor. Bioorg Med Chem Lett. 2009; 19: 6004-08.

Weinrich SL, Pruzan R, Ma L, Ouellette M, Tesmer VM, Holt SE, Bodnar AG, Lichtsteiner S, Kim NW, Trager JB, Taylor RD, Carlos R, Andrews WH, Wright WE, Shay JW, Harley $\mathrm{CB}$, Morin GB. Reconstitution of human telomerase with the template RNA component hTR and the catalytic protein subunit hTRT. Nature Genetics. 1997; 17: 498-502.

Xia J, Peng Y, Mian IS, Lue NF. Identification of functionally important domains in the $\mathrm{N}$-terminal region of telomerase reverse transcriptase. Mol Cell Biol. 2000; 20: 5196-207.

Yan D, Jin C, Xiao XH, Dongh XP. Antimicrobial properties of berberine alkaloids in CoPtis chinensis Franch by microcalorimetry. J Biochem Biophys Methods. 2007; 70: 845-49.

Zhang $\mathrm{H}$, Wei J, Xue R, Wu JD, Zhao W, Wang ZZ, Wang SK, Zhou ZX, Song DQ, Wang YM, Pan HN, Kong WJ, Jiang JD. Berberine lowers blood glucose in type 2 diabetes mellitus patients through increasing insulin receptor

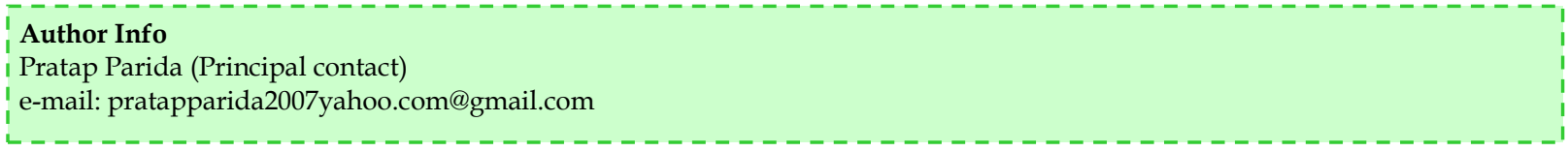

